\title{
USABILIDADE DO BIKE PE NO CAMPUS DA UFPE
}

\author{
Mauro Pessôa Carneiro (1); \\ Erilze Brito(2); \\ Mônica Uchôa Cavalcanti(3); \\ Marcelo M. Soares (4)
}

\begin{abstract}
Universidade Federal de Pernambuco
(1); (2); (3) Mestrandos em Ergonomia

emails: erilzebritto@yahoo.com.br; mautiger@hotmail.com; monicauchoaufpe@gmail.com
\end{abstract}

(4) Ph.D. em Ergonomia

e-mail: soaresmm@gmail.com

\begin{abstract}
RESUMO
Este artigo apresenta a análise da usabilidade do Bike PE, sistema de estações de bicicletas, sob o enfoque da ergonomia. Neste processo ergonômico evidencia-se a usabilidade do sistema, como meio consistente para detectar problemas encontrados no decorrer das tarefas. O sistema Bike PE é um programa do Governo do Estado de Pernambuco, em parceria com as Empresas Serttel/Samba e apoio do Banco Itaú, com o intuito de introduzir a bicicleta como transporte público sustentável, saudável e não poluente, como também o sedentarismo da população. Nos resultados apresentou-se sugestões de melhorias, preocupando-se com a eficiente e eficácia na usabilidade do sistema de estações de bicicleta Bike PE, centrado na satisfação do usuário.
\end{abstract}

Palavras-chave: Ergonomia. Usabilidade. Sistemas.Estações de bicicletas.

\section{ABSTRACT}

This article presents the analysis of usability of the Bike PE, bike stations system in view of ergonomics. This ergonomic analyzes highlights the system's usability as a way consistent to detect problems encountered during the tasks. The Bike PE system is a Government of the State of Pernambuco program, in partnership with Serttel Companies / Samba and support of Banco Itaú, in order to introduce the bicycle as a sustainable public transport, healthy and clean, as well as avoiding idleness of the population. The results presented are suggestions for improvements, concerned with the efficient and effective usability Bike PE bike stations system, focused on user satisfaction.

Keywords: Ergonomics. Usability. Sistems. Bike stations. 


\section{INTRODUÇÃO}

Para que um produto tenha boa usabilidade, recomenda-se que ele seja construído a partir de uma perspectiva do design centrado no usuário, visando atender às suas expectativas e necessidades informacionais. Atualmente a preocupação com a qualidade de vida e do ambiente tem sido assunto de destaque em praticamente todos os cenários, nacional e mundial. Alguns países já adotaram mudanças das mais diversas para tentar frear o desgaste do ambiente que afeta todo o planeta, sendo responsabilidade de todos. Dentre estas medidas estão a da melhoria na mobilidade em centros urbanos e da qualidade do ar através do estímulo de transportes públicos, a exemplo dos metrôs ou dos meios compartilhados como ocorre com o aluguel de veículos seja individualmente ou através do sistema de carona. Tudo em prol da satisfação do usuário real e potencial.

Como exemplo, temos os projetos das chamadas bicicletas compartilhadas, inspirado em experiências internacionais. Este sistema foi introduzido no país em 2011, inicialmente na cidade do Rio de Janeiro (BikeRio) e diante de seu sucesso houve sua expansão para mais 11 cidades brasileiras, como foi o caso do Bike PE em Recife, em 2013.

O Bike PE é um sistema de bicicletas públicas que visa oferecer ao Estado de Pernambuco, um transporte sustentável e não poluente, implantado pelas empresas Serttel/Samba apoiadas pelo Banco Itaú.

O Sistema Público de Compartilhamento de Bicicletas BIKE PE é disponibilizado pelo Consorcio Bike PE, formado pelas empresas Serttel Ltda e Samba Transportes Sustentáveis Ltda, ambas operadoras, tendo o Banco Itaú Unibanco S.A., como patrocinador e a Empresa Mobilicidade Tecnologia Ltda, como empresa responsável pelo armazenamento e gestão em base de dados de usuários e pelas transações eletrônicas para comercialização de passes para uso do sistema.

Com relação ao aparato tecnológico, o sistema conta com estações de bicicletas, site de internet, canais de atendimento e software representado por um aplicativo para aparelhos móveis que garantem a operação, o usuário deverá adquirir passes que permitirão o uso das bicicletas, mediante prévio cadastro no site (www.bikepe.com.br), mediante o preenchimento de um formulário e o aceite das condições do termo de uso.

Neste estudo analisou-se a usabilidade do sistema Bike PE (Painel/Display), verificando a eficácia, eficiência do sistema; motivação e satisfação do usuário das estações de bicicletas. O sistema analisado funciona no campus da Universidade Federal de Pernambuco, com o propósito de viabilizar a locomoção dos usuários, contendo um total de três estações, sendo: uma no Centro de Ciências da Saúde (CCS: Estação 78), outra no Núcleo de Integração de Atividade de Ensino (NIATE I: Estação 79), e a outra no Centro de Artes e Comunicação (CAC: Estação 80).

Segundo Santos (2002, p.60), usabilidade pode ser compreendida como a capacidade, em termos funcionais humanos, de um sistema ser usado facilmente e com eficiência pelo usuário.

lida (2005, p.320) ainda complementa que: "Portanto, a usabilidade depende da interação entre o produto, o usuário, a tarefa e o ambiente".

Jordan (1998, p. 25, tradução nossa) "[...] define, então, dez princípios relacionados à usabilidade de produtos que devem direcionar o processo de desenvolvimento destes, na tentativa de assegurar o projeto do produto que interaja adequadamente, como: [...] consistência, compatibilidade, capacidade, feedback, prevenção e correção dos erros, controle ao usuário, clareza visual, priorização da funcionalidade e da informação, transferência adequada de tecnologia e evidência. 


\section{METODOLOGIA}

\subsection{Objeto do Estudo}

Foi realizada a observação in loco, na estação Bike PE, de bicicletas que funcionam no campus da UFPE, registrando os procedimentos do usuário. A pesquisa de campo requer uma certa disponibilidade do usuário e do entrevistador. As técnicas utilizadas para levantamento de campo foram às observações e entrevistas.

As observações sistemáticas permitiram avaliar o espaço de trabalho em seus aspectos funcionais e bioclimáticos, [...] também, levantar o comportamento do usuário, em termos gestuais, informacionais, cognitivos e de regulação. (FIALHO, 2005, p. 70)

Analisou-se a usabilidade do produto Bike PE, através do sistema de liberação (Painel/Display) de bicicletas das estações localizadas dentro do campus da Universidade Federal de Pernambuco, verificando a eficácia, eficiência do sistema; motivação e satisfação do usuário.

\subsection{Configurações da estação}

A estação Bike PE é composta na sua parte central (aproximadamente 1,80 m de altura) por um painel computadorizado que é alimentado por uma placa de energia solar que se comunica através de uma rede wireless. Este painel possui instruções de uso em português, inglês e espanhol, mapa com localização e indicação de todas as estações e detalhamento das mais próximas. Estações localizadas fora do município aparecem apenas o número sem descrição.

Horizontalmente há uma barra de metal na qual as bicicletas ficam presas ou são liberadas por meio de um dispositivo eletromecânico de travamento e liberação (Figura 1). Também existem lâmpadas de sinalização de cor verde que acendem indicando que a bicicleta está destravada e pode ser retirada, com mensagem indicando a posição da bicicleta que o usuário deverá retirar.

A liberação da bicicleta é via cartão Vale Eletrônico Metropolitano (VEM) e aplicativos inteligentes para telefone celular. O usuário deverá adquirir os passes de acesso através de cadastro no site (www.bikepe.com.br).

O Horário de funcionamento da estação é das 5 h até $23 \mathrm{~h}$. , de domingo a domingo.

O tempo de uso das bicicletas é de 60 minutos, mas o ciclista pode fazer várias utilizações por dia, desde que obedeça ao intervalo de 15 minutos entre os empréstimos, e para emprestar é preciso pagar um valor diário de $R \$ 5,00$, ou mensal por $R \$ 10,00$.

Abaixo, segue a fotografia (Figura 1) da estação número 80 , localizada na UFPE, esquina do Centro de Artes e Comunicação, e em frente ao restaurante universitário. 
Figura 1 - Estação Bike PE

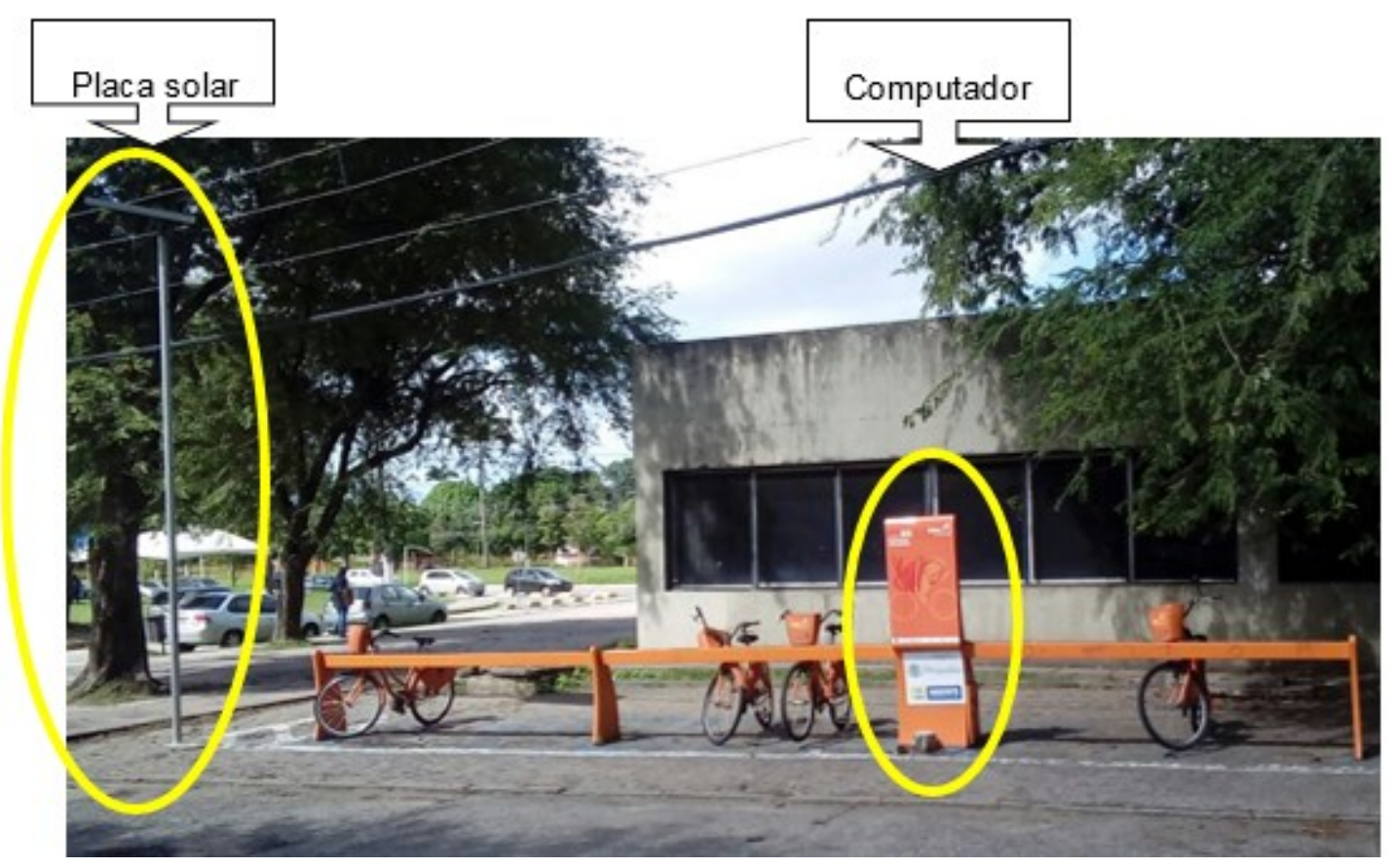

Ainda no painel, ficam localizados um display (Figura 2), o qual o usuário precisa ficar atento à sua leitura para realizar corretamente os passos necessários para liberação da bicicleta e um indicador luminoso que fica verde quando a estação está online e vermelho nas situações off-line.

Figura 2 -Torre de acesso com painel da estação com instruções

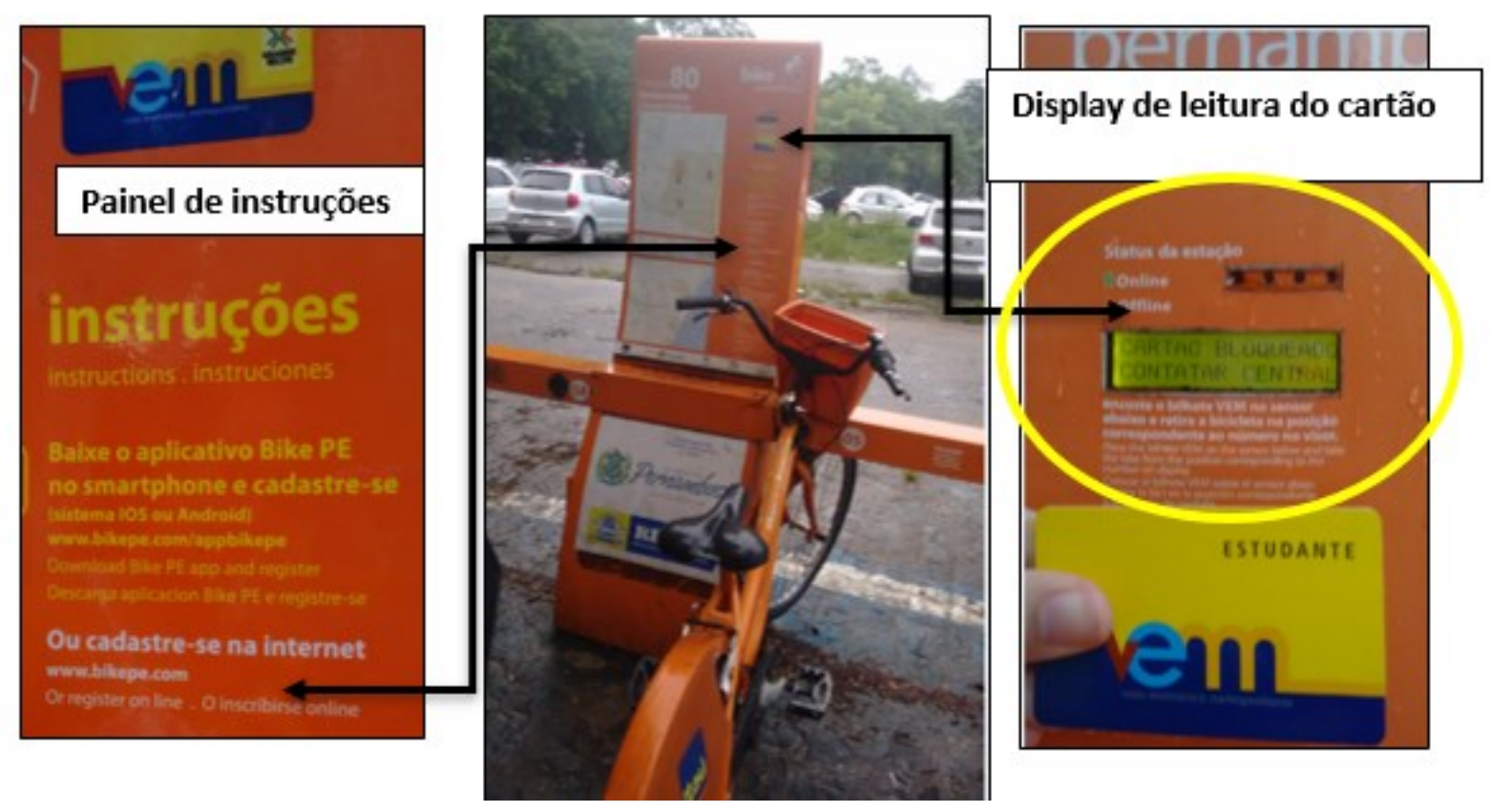


Além da informação contida no display (Figura 3), na leitura do cartão, pode ocorrer várias outras orientações que seguem uma sequência lógica positiva: apresente seu cartão; aguarde; confirma retirada, posição 12 liberada; e uma sequência negativa, dependendo da situação do cartão de cada usuário, cartão em uso (identifica a bicicleta disponível); estação off-line, confirmar c/ tarifação?; aguarde; bicicleta indisponível.

\section{Figura 3 - Informações no Display}

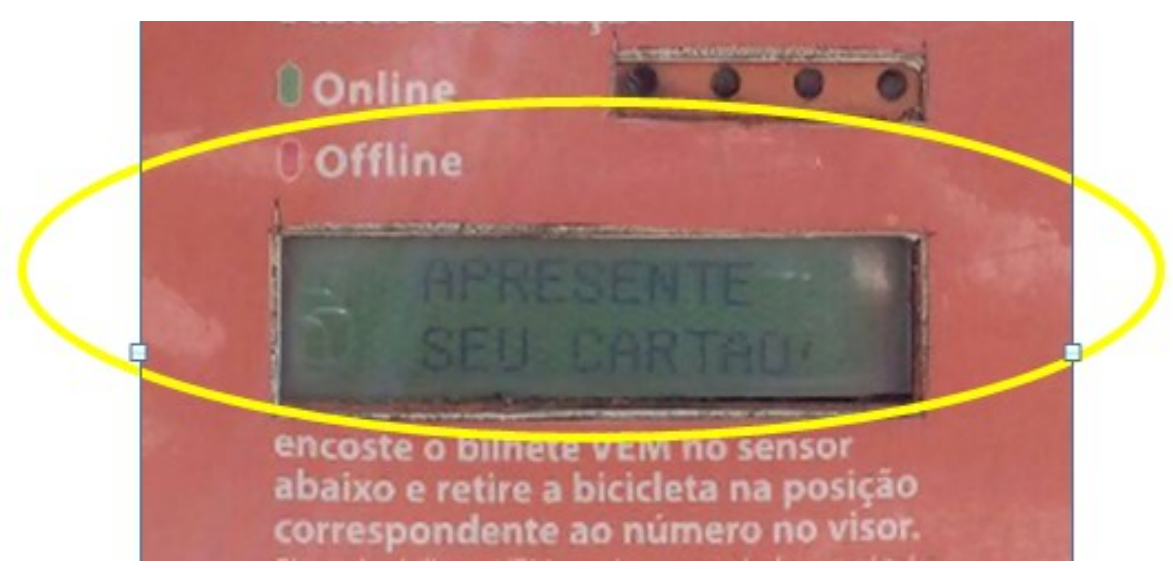

Figura 4 - Painel da estação $n^{\circ} 78$ e descrição das informações no painel

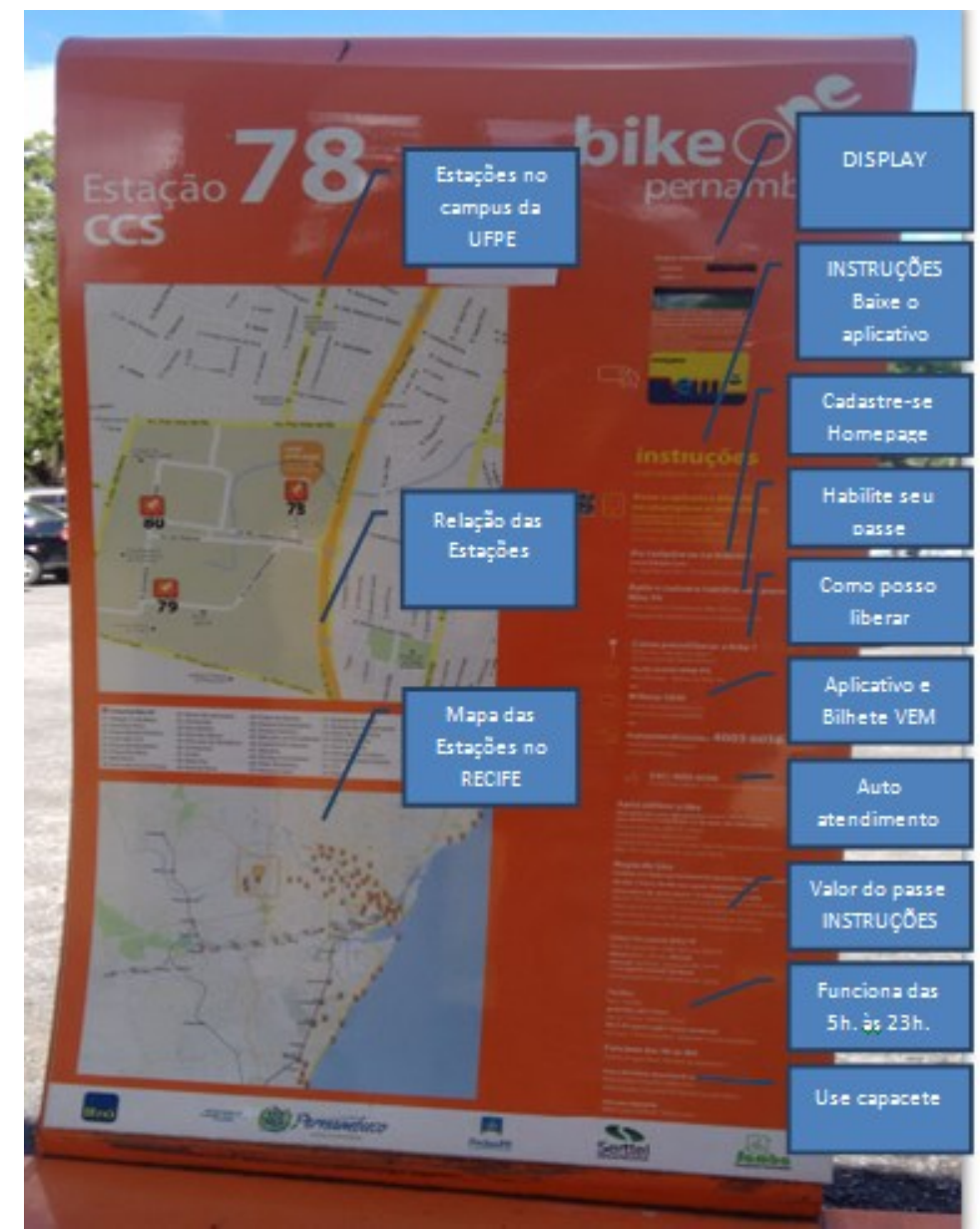




\subsection{Desenho do Estudo}

Usou-se a metodologia analítica e descritiva, quantitativa e qualitativa, onde os usuários participam com interação conversacional e com registros de feedback. Registrou-se durante os procedimentos da usabilidade: facilidade de aprendizagem, facilidade de uso, boa adequação à tarefa, nível de satisfação do usuário e aspectos de cognição. Aplicou-se entrevistas com perguntas abertas.

\subsection{Amostragem}

Participaram:

- Usuários novatos: 2 funcionários da UFPE que nunca usaram o sistema Bike PE;

- Usuários intermediários: 2 alunos da UFPE que usam o sistema Bike PE ocasionalmente;

- Usuários experientes: 2 alunos da UFPE, que usam frequentemente o sistema Bike PE.

De modo geral, observou-se que os usuários principais são alunos e funcionários da UFPE, mas o sistema também atende a comunidade do entorno da UFPE. Documentou-se o perfil do usuário, sem levar em consideração: idade, sexo, características físicas.

\subsection{Coleta de Dados}

Para coleta de dados foram feitas entrevistas com usuários na estação Bike PE. O entrevistador sempre se apresentava e explicava o objetivo do estudo, solicitava permissão para realizar as fotografias do usuário usando o sistema e os diversos procedimentos. $O$ questionário incluía perguntas abertas e fechadas: sobre o usuário (nome, vínculo na UFPE, percurso pretendido, usabilidade da Bike PE); sobre o sistema Bike PE (dificuldades de acesso ao sistema, facilidade de aprendizado, utilização, problemas identificados).Medição de tempo gasto na ação de usuário já cadastrado através da homepage: 10 minutos.

Contactou-se com a empresa Serttel a fim de coletar dados sobre a manutenção das estações e a empresa afirmou que executa rotinas preventivas e corretivas para garantir altos índices operacionais de desempenho e confiabilidade nas estações de bicicletas. As manutenções são pontuais para garantir o bom funcionamento do sistema. Os equipamentos são inspecionados diariamente, componentes são substituídos de uma forma preventiva, evitando interrupções de serviço e falhas operacionais.

\subsection{Variáveis Observacionais de Campo}

$\mathrm{Na}$ figura 5, abaixo a usuária realizou os procedimentos para liberação da bicicleta, e a mesma reclamou que o sistema wireless estava lento, o display mostra posição 12 liberada mas não ocorreu o destravamento da bicicleta, tentou novamente, mas não conseguiu.

Foi utilizado o cartão VEM, porém o mesmo precisa ter crédito e/ou passe para liberação da bicicleta, bastando encostar o cartão no código de identificação para leitura no display. 


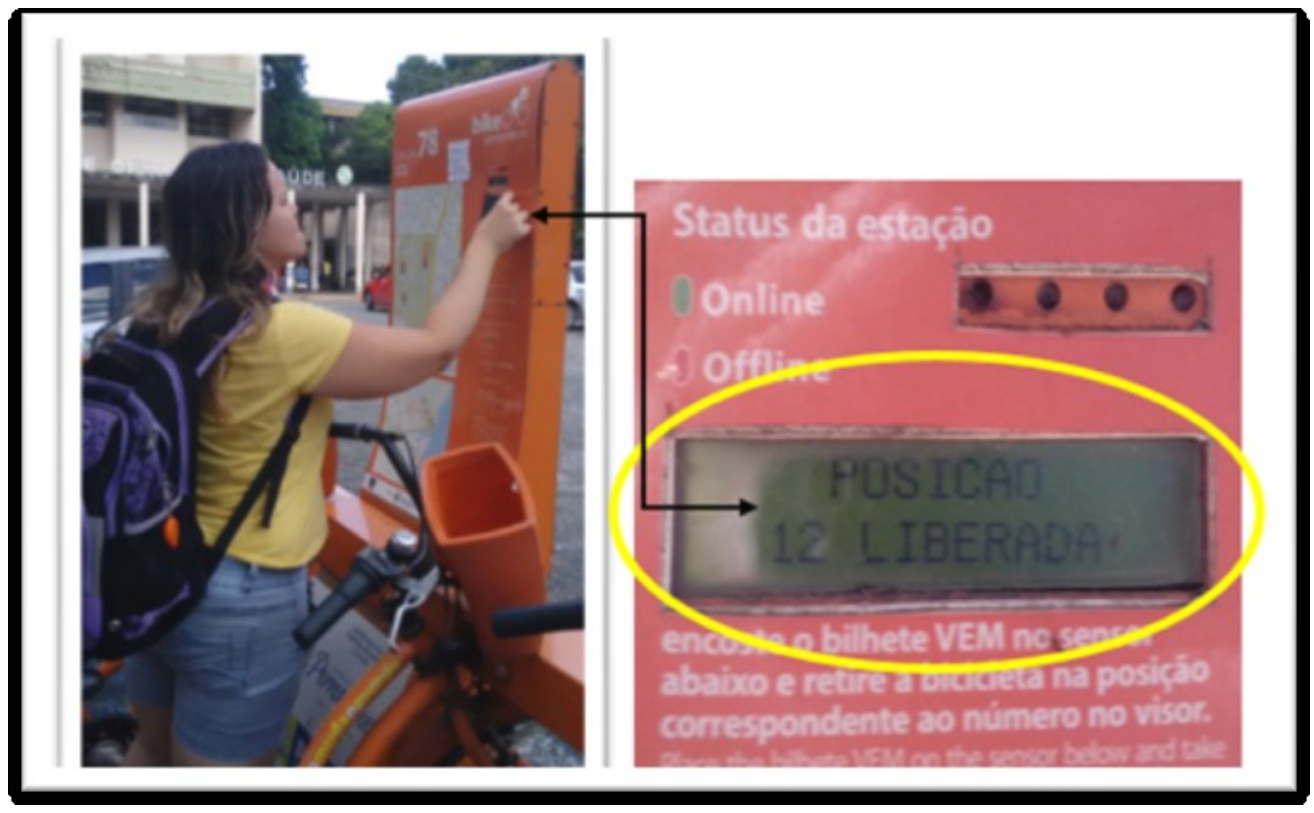

Na figura 6, as telas no celular são sequências do aplicativo para cadastramento de cartão de crédito e aquisição de passes para liberar a Bike PE. Ao aparecer no celular o símbolo da Bike PE, é só clicar no ícone e seguir os passos. Verificou-se os procedimentos realizados pelo usuário, e o mesmo reclamou que o sistema wireless, estava lento. O usuário se afastou para acessar, foi para dentro do centro, depois voltou correndo para pegar a bicicleta e não conseguiu, tentou novamente e acessou via aplicativo, em seguida retirou a bicicleta. Levou 22 minutos na operação de retirada da bicicleta.

Figura 6 - Acesso ao sistema Bike PE via aplicativo de celular
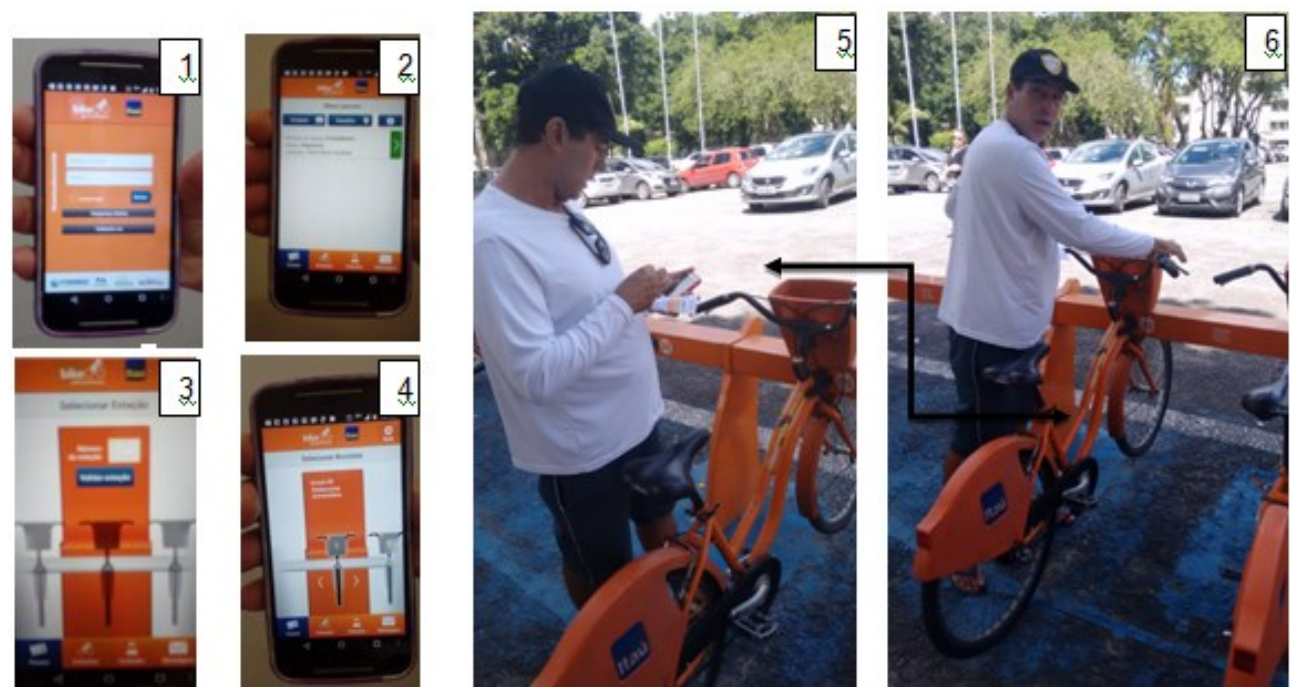


\section{RESULTADOS E DISCUSSÕES}

Uma vez que na própria estação existem informações escritas de como utilizá-la evitou-se interferir no procedimento, pois desta forma pode-se testar também o conteúdo das instruções com relação a caracterizar se é de fácil, médio ou de difícil entendimento para o usuário. Notou-se que os usuários novatos ficaram um pouco apreensivos, porém com o tempo iam desenvolvendo habilidade de uso (observação comportamental).

$\mathrm{Na}$ observação procurou-se medir o tempo total gasto para realizar todas as etapas das tarefas, estabelecendo para tanto um tempo máximo de 10 minutos, uma vez que trata-se de um processo com poucas etapas. Os usuários que não completaram as etapas em menos de 10 minutos foram identificados como usuários que não completaram a tarefa.

Verificou-se ainda o número de erros cometidos por cada um deles, identificando desta maneira se é de fácil ou difícil aprendizado. Após a utilização do produto e de todas as etapas da tarefa, procedeu-se à entrevista aos usuários, composta de perguntas abertas e fechadas representadas em escalas de 1 a 5 . Com o objetivo de identificar melhorias na estação, através de observações e testes de usabilidade realizados pelos voluntários, seguem as propostas mais imediatas de melhorias abaixo, através de um quadro aonde são identificados problemas, consequências do problema no ser humano, tipo de problema, limitações do sistema e sugestões de melhoria (Quadro 1).

\section{Quadro 1 - Problematização}

\begin{tabular}{|c|c|c|c|c|c|}
\hline \multicolumn{6}{|c|}{ PROBLEMATIZAÇÃO } \\
\hline & Problemas & $\begin{array}{l}\text { Problemas } \\
\text { Humanos }\end{array}$ & $\begin{array}{l}\text { Custos } \\
\text { Humanos }\end{array}$ & $\begin{array}{l}\text { Limitações do } \\
\text { Sistema }\end{array}$ & Sugestões \\
\hline 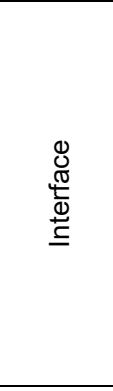 & $\begin{array}{l}\text {-Display: pequeno } \\
\text { e alto } \\
\text {-Painel: Fonte } \\
\text { muito pequena. } \\
\text {-Muita } \\
\text { informação no } \\
\text { painel,repetidas } \\
\text { e desnecessária. }\end{array}$ & $\begin{array}{l}\text {-Dificuldades na } \\
\text { leitura do display. } \\
\text {-Usuário baixo não } \\
\text { alcança as } \\
\text { mensagens } \\
\text {-Usuário não } \\
\text { enxerga as } \\
\text { mensagens no } \\
\text { display. } \\
\text {-Usuário se perde } \\
\text { nas informações } \\
\text { do painel. } \\
\end{array}$ & $\begin{array}{l}\text {-Estresse } \\
\text {-Fadiga }\end{array}$ & $\begin{array}{l}\text {-Prevenção de } \\
\text { erros. } \\
\text { - Call Center }\end{array}$ & $\begin{array}{l}\text {-Aumento do display. } \\
\text {-Baixar painel } \\
\text {-Aumentar fontes }\end{array}$ \\
\hline 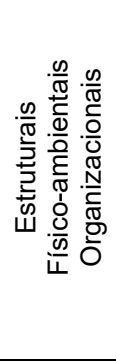 & $\begin{array}{l}\text { - Sem proteção } \\
\text { para estação } \\
\text { visando } \\
\text { preservação dos } \\
\text { equipamentos } \\
\text { - Sem prevenção } \\
\text { para vandalismo } \\
\text { - Sem } \\
\text { comunicação } \\
\text { imediata }\end{array}$ & $\begin{array}{l}\text { - Dificuldades para } \\
\text { leitura das } \\
\text { mensagens (Sol) } \\
\text { - Design da } \\
\text { informação no } \\
\text { painel, poluição } \\
\text { visual. }\end{array}$ & -Estresse & $\begin{array}{l}\text { - Depredação do } \\
\text { painel. } \\
\text { - Sistema: fora do } \\
\text { ar. } \\
\text {-Estação off-line }\end{array}$ & $\begin{array}{l}\text {-Reorganização do } \\
\text { design da } \\
\text { informação no } \\
\text { painel } \\
\text {-Coberta para a } \\
\text { estação } \\
\text {-Monitoramento } \\
\text { através de câmera } \\
\text { no equipamento }\end{array}$ \\
\hline 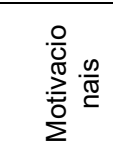 & $\begin{array}{l}\text { - Falha no cartão } \\
\text { VEM } \\
\text { - Falha no } \\
\text { aplicativo. }\end{array}$ & $\begin{array}{l}\text {-Não tem respostas } \\
\text {-Várias tentativas } \\
\text { para realizar a } \\
\text { ação. }\end{array}$ & $\begin{array}{l}\text {-Fadiga } \\
\text {-Insatisfação }\end{array}$ & $\begin{array}{l}\text {-Central telefônica, } \\
\text { matriz em São } \\
\text { Paulo. } \\
\text {-Manutenção lenta. }\end{array}$ & $\begin{array}{l}\text {-Fale conosco, } \\
\text { resposta imediata }\end{array}$ \\
\hline 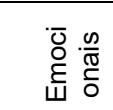 & $\begin{array}{l}\text {-Oscilação na } \\
\text { comunicação. }\end{array}$ & $\begin{array}{l}\text {-Não finaliza a } \\
\text { tarefa. }\end{array}$ & -Insatisfação & $\begin{array}{l}\text { - Rede Wireless } \\
\text { lenta. }\end{array}$ & $\begin{array}{l}\text {-Verificar a rede } \\
\text { wireless, fazer } \\
\text { parceria com a UFPE. }\end{array}$ \\
\hline
\end{tabular}

Exemplos de alguns problemas identificados estão nas próximas figuras. Na figura 7, o usuário espera feedback do sistema encostando o cartão VEM, mas o painel está rasgado, 
sem funcionamento do sistema, então aparece a mensagem: "Sem bicicleta disponível". Constatou-se que o painel tinha sido depredado, rasgado.

Figura 7 - Problemas de depredação do painel

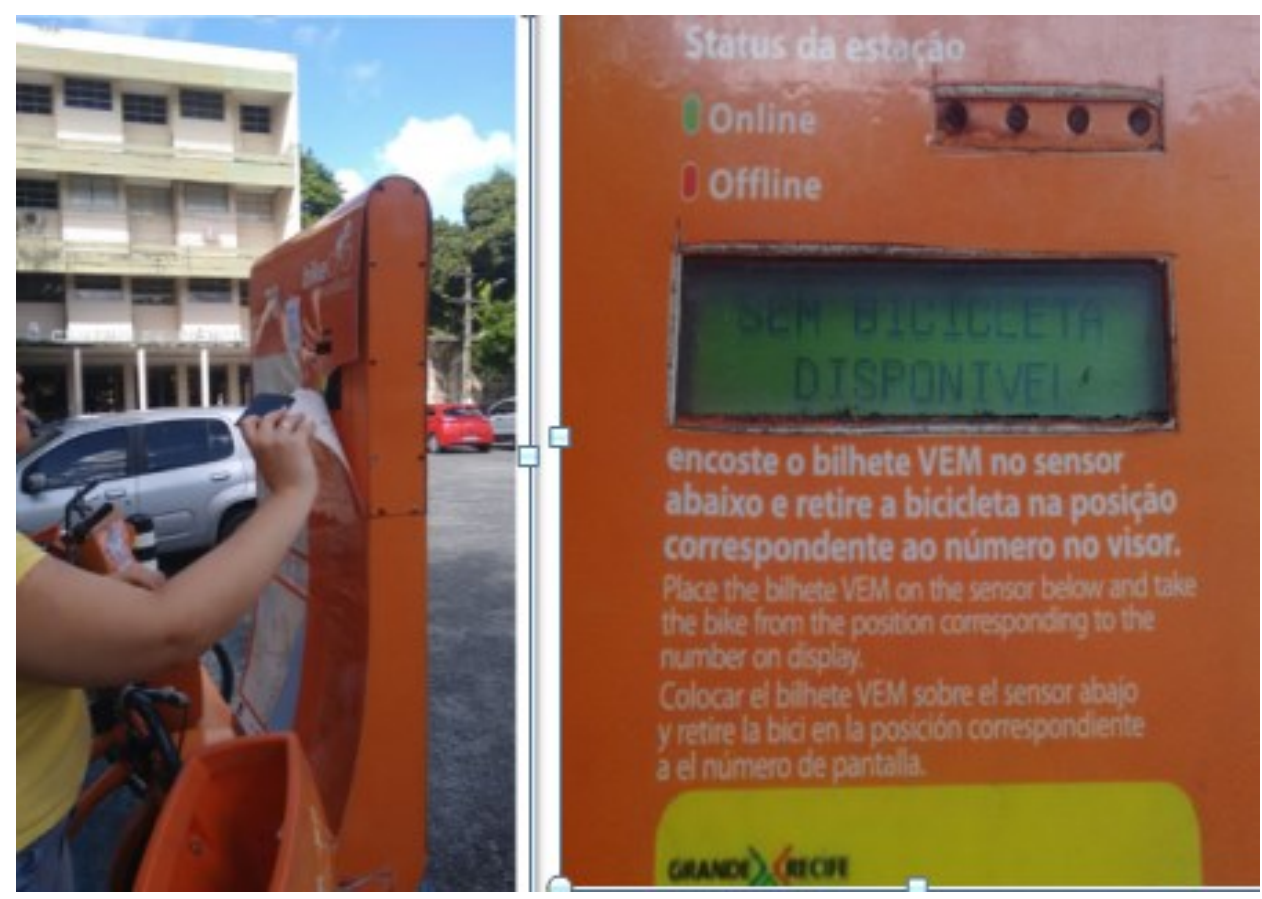

Na figura 8, demonstrou-se o uso do VEM estudante e VEM trabalhador, ambos indicaram resposta do display: cartão bloqueado e bicicleta indisponível. Neste caso, o usuário não tem passe no cartão e não tem bicicleta disponível para uso.

Os usuários se queixaram dos mais variados problemas, que foram desde falhas sistêmicas até equipamentos quebrados e sem manutenção.

Figura 8 - Feedback do display na leitura do cartão
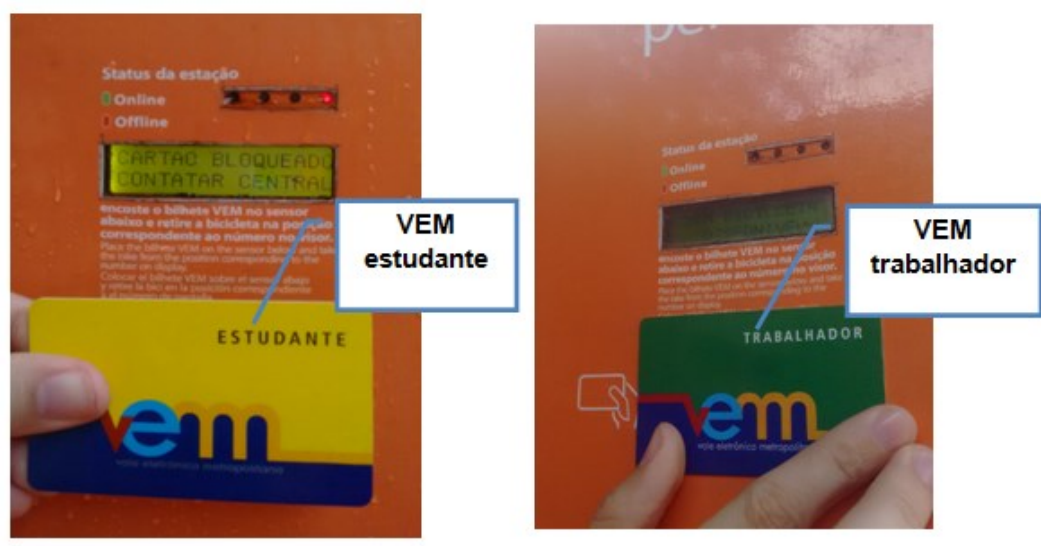


\section{RECOMENDAÇÕES PARA OS PROBLEMAS IDENTIFICADOS}

A seguir encontram-se recomendações para os diversos problemas encontrados:

Display pequeno e alto para leitura do cartão VEM; as fontes são pequenas, pois pessoas de estatura mais baixa têm dificuldades para conseguir ler as informações:

- sugeriu-se diminuir a altura do display para 1,60 m e aumentar as fontes do display.

As fontes do painel são pequenas; muita informação no painel é desnecessária, como mapa das estações no Recife:

- recomendou-se reduzir as informações do painel, reformular o design da informação e colocar ícones, simplificando as informações e instruções de uso.

Sem proteção para estação visando à preservação dos equipamentos contra as ações do tempo (chuva, sol, reflexo da luz, etc.):

- sugeriu-se coberta, estilo abrigo, para toda estação visando minimizar as ações do tempo;

Sem prevenção para vandalismo, as estações, o painel, o display, as bicicletas sofrem depredações:

- sugeriu-se a instalação de câmeras acopladas para sistema de monitoramento, como forma de disciplinar a ação do usuário insatisfeito;

Sem comunicação imediata, no caso do display não funcionar, feedback não é imediato, principalmente quando a estação está off-line, e outros pormenores:

- recomendou-se instalar telefone para contato imediato para a central de atendimento ao cliente;

Oscilação na comunicação, demora na resposta da leitura do cartão VEM:

- recomendou-se uma tecnologia mais avançada em parceria com a UFPE.

\section{CONSIDERAÇÕES FINAIS}

O estudo mostrou-se promissor. A amostra foi pequena, mas muito significativa, considerando que as recomendações ergonômicas foram relevantes, visando uma ampla divulgação dos resultados para as empresas parceiras. Consideramos que se faz necessário novos estudos com maior amostra para posterior validação a fim de estabelecer uma maior eficácia dos testes.

A análise dos dados obtidos neste estudo de campo foi complexa, devido à pressa do usuário de se deslocar de um local para outro a fim de realizar a sua mobilidade, porém satisfatório no sentido de que os usuários conseguiram verbalizar sua satisfação ou insatisfação, através das entrevistas realizadas.

Até o presente, desconhecemos outro estudo que tenha avaliado o sistema Bike PE, motivo o qual não temos um referencial teórico amplo sobre este sistema especificamente.

Identificada a problematização do sistema Bike PE, abaixo demonstrou-se através da figura 9, o modelo físico estrutural recomendado, de como deveria funcionar o sistema Bike PE, com uma estrutura básica necessária para a usabilidade adequada das estações no campus 
da UFPE, podendo servir de modelo para as demais estações instaladas na Região Metropolitana do Recife.

Figura 9 - Modelo físico estrutural recomendado

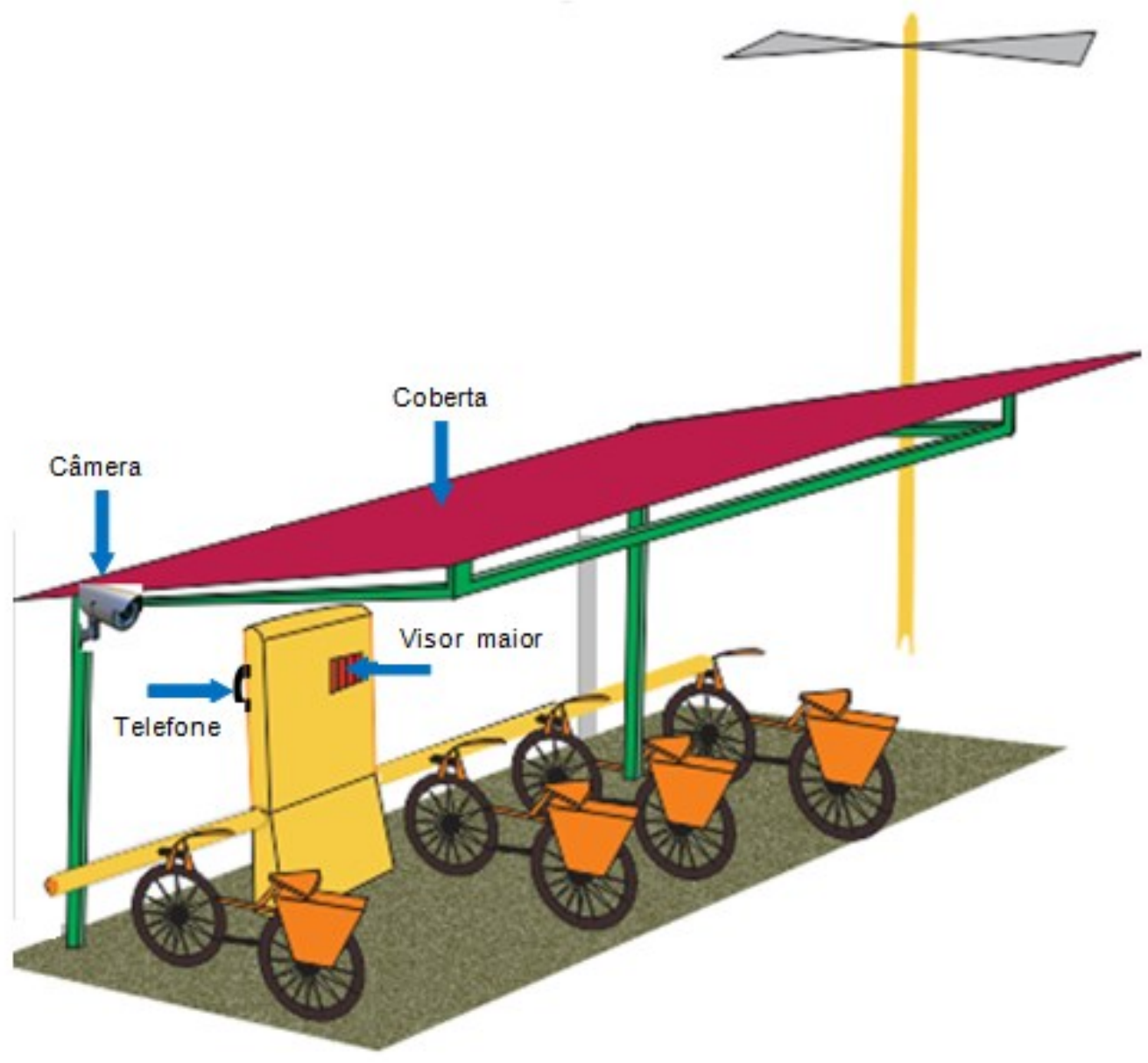

\section{REFERÊNCIAS}

FIALHO, Francisco A. P. Métodos e técnicas em ergonomia. Florianópolis: Edições dos autores, 2005.

IIDA, Itiro. Ergonomia: projeto e produção. 2. ed. São Paulo: Blucher, 2005.

JORDAN, Patrick W. An introduction to usability. Philadelphia (USA): Taylor \& Francis, 1998.

SANTOS, R. L. G. dos S. Abordagem Heurística para avaliação da usabilidade de interfaces. Design e avaliação de interface. In: MORAES, Ana Maria de. Design e avaliação de interface: ergodesign e interação humano-computador. Rio de Janeiro: IUsEr, 2002. 